\title{
Application of the British Food Standards Agency nutrient profiling system in a French food composition database
}

\author{
Chantal Julia ${ }^{1,2 *}$, Emmanuelle Kesse-Guyot ${ }^{1}$, Mathilde Touvier $^{1}$, Caroline Méjean ${ }^{1}$, Léopold Fezeu ${ }^{1}$ and \\ Serge Hercberg ${ }^{1,2}$ \\ ${ }^{1}$ Université Paris 13, Equipe de Recherche en Epidémiologie Nutritionnelle (EREN), Centre de Recherche en Epidémiologie \\ et Biostatistiques Sorbonne Paris Cité (CRESS), UMR 1153 Inserm, U1125 Inra, Cnam, Université Paris 5, Université Paris 7, \\ 74 rue Marcel Cachin, \\ F-93017 Bobigny Cedex, France \\ ${ }^{2}$ Département de Santé Publique, Hôpital Avicenne (AP-HP), Bobigny, France
}

(Submitted 25 February 2014 - Final revision received 25 July 2014 - Accepted 6 August 2014 - First published online 2 October 2014)

\section{Abstract}

Nutrient profiling systems are powerful tools for public health initiatives, as they aim at categorising foods according to their nutritional quality. The British Food Standards Agency (FSA) nutrient profiling system (FSA score) has been validated in a British food database, but the application of the model in other contexts has not yet been evaluated. The objective of the present study was to assess the application of the British FSA score in a French food composition database. Foods from the French NutriNet-Santé study food composition table were categorised according to their FSA score using the Office of Communication (OfCom) cut-off value ('healthier' $\leq 4$ for foods and $\leq 1$ for beverages; 'less healthy' $>4$ for foods and $>1$ for beverages) and distribution cut-offs (quintiles for foods, quartiles for beverages). Foods were also categorised according to the food groups used for the French Programme National Nutrition Sante (PNNS) recommendations. Foods were weighted according to their relative consumption in a sample drawn from the NutriNet-Santé study ( $n$ 4225), representative of the French population. Classification of foods according to the OfCom cut-offs was consistent with food groups described in the PNNS: $97.8 \%$ of fruit and vegetables, $90.4 \%$ of cereals and potatoes and only $3.8 \%$ of sugary snacks were considered as 'healthier'. Moreover, variability in the FSA score allowed for a discrimination between subcategories in the same food group, confirming the possibility of using the FSA score as a multiple category system, for example as a basis for front-of-pack nutrition labelling. Application of the FSA score in the French context would adequately complement current public health recommendations.

Key words: Nutrient profiling systems: Applications: Food composition

An 'unhealthy' diet is one of the major drivers of chronic diseases in the Western world ${ }^{(1,2)}$. Being aware of the existing challenge of preventing chronic diseases, most Western countries have invested in state-level public health nutrition programmes ${ }^{(3-5)}$. Most initiatives use nutritional education or communication, promoting the consumption of certain food groups (fruit and vegetables, whole-grain cereals and water) and warning against excessive intakes of other food groups or of specific nutrients (snack products, saturated fat, added sugar and $\mathrm{Na})^{(6)}$.

Since 2000, France has developed one such public health nutrition programme, the Programme National Nutrition Santé (PNNS, French Nutrition and Health Program), which is aimed at improving the health of the whole population by acting on nutrition $^{(7)}$. The programme combines synergistic, complementary and consistent actions, measures, regulations and laws. Regular vast national multimedia campaigns and broadly disseminated national food-based guides ${ }^{(8)}$ relay public health messages, encouraging the consumption of certain food groups ('at least five fruit and vegetables a day' and 'bread and cereals at each meal according to appetite') and recommending the limited consumption of other food groups ('avoid eating foods that are too salty, too sugary or too fatty' and 'avoid snacking'). Recommendations pertaining to the consumption of meat and alternatives and dairy products are intermediate ('meat, fish and alternatives should be consumed once or twice a day' and 'three dairy products a day').

Beyond nutritional recommendations concerning broad categories of food, some have argued for further scoring of individual foods, through nutrient profiling systems ${ }^{(6,9)}$. Nutrient profiling systems aim at positioning individual foodstuffs based on their nutritional composition ${ }^{(10)}$ Nutritional information is therefore simplified in a single

Abbreviations: FSA, Food Standards Agency; PNNS, Programme National Nutrition Santé.

*Corresponding author: C. Julia, fax + 33 148388931, email c.julia@uren.smbh.univ-paris13.fr 
score, taking into account various components of the food. Potential applications of nutrient profiling systems to public health initiatives are multiple: they could be used as a support for front-of-package nutritional information; as a tool to regulate advertising of foods; as a basis to implement food taxes or subsidies ${ }^{(11)}$. Multiple nutrient profiling systems have been developed $^{(9,12)}$, one of the most advanced being the British nutrient profiling system developed by the Food Standards Agency (FSA), hereafter termed the FSA score ${ }^{(13)}$.

The FSA score was developed in order to regulate advertising of foods and beverages to children in the $\mathrm{UK}^{(13,14)}$. The model has since been applied with other objectives ${ }^{(15)}$ and has been found to be applicable to adults as well ${ }^{(16)}$. For each food or drink, a score is provided according to their content in energy, total sugar, $\mathrm{Na}$ and saturated fat, balanced by their content in fruits, vegetables and nuts, fibres and proteins ${ }^{(13)}$. Individual scores range from -15 (most healthy) to 40 (less healthy) (see online supplementary Table S1 for details on score computation). Cut-offs have been established by the Office of Communication to categorise foods and drinks as 'healthier' and 'less healthy', and the latter are not allowed for advertising to children ${ }^{(13)}$.

The FSA scoring system has been validated in the British National Diet and Nutrition Survey food database ${ }^{(17)}$, but the application of the model in other contexts has not yet been tested. The objective of the present study was to investigate the application of the FSA score in a French food composition database, and to assess its consistency with PNNS food groups, relating it to French recommendations ${ }^{(8)}$. We hypothesised that foods belonging to food groups for which consumption is encouraged by the PNNS (fruit and vegetables, bread and cereals) would have lower scores than those belonging to food groups for which consumption should be limited (fats, sugary and salty snacks). We further hypothesised that the variability in the continuous FSA score within foods would allow for a discrimination between subcategories of foods (e.g. within the 'milk and dairy products', milk and yogurt would have a lower score than cheese), and that its use in multiple categories (i.e. five categories) would prove an alternative and adequate support for its use.

\section{Materials and methods}

\section{Data collection}

Food composition data. Data were obtained from the NutriNet-Santé study. Briefly, the NutriNet-Santé study is a French prospective observational cohort study in which inclusion and follow-up of volunteer subjects are performed on the Internet. The main objectives of the NutriNet-Santé study are (1) to investigate the relationship between nutrition and health outcomes, and (2) to study the role of various determinants of dietary patterns and nutritional status, and their interactions. Inclusion in the study began in May 2009, and is still ongoing. Volunteer subjects aged $>18$ years old subscribe to the study, and are considered included when they have completed a set of questionnaires assessing: diet, physical activity, anthropometry, lifestyle, socio-economic conditions and health status. Detailed information on the methods used in the NutriNet-Santé study can be found elsewhere ${ }^{(18)}$.

All foods and drinks that were declared to be consumed by the participants in the study have a correspondence as a 'generic' food in the NutriNet-Sante food composition database. This database reflects usually consumed foods in the French diet ${ }^{(19)}$. The food composition database contains also the composition of some branded foods. Food consumption for each participant is calculated taking into account the composition of the 'generic' food.

Dietary data. A sample of 4225 subjects representative of the French population (for sex, age and level of education), and having completed three $24 \mathrm{~h}$ dietary records, was drawn from subjects in the NutriNet-Santé study. Dietary data derived from these $24 \mathrm{~h}$ records were used to compute the relative proportion in which each food was consumed.

\section{Variable computation}

Programme National Nutrition Santé food categories. Foods were categorised according to the food groups described in the PNNS food guidelines ${ }^{(8)}$ into nine broad food classes: food groups for which consumption is encouraged - 'fruit and vegetables', 'cereals and potatoes'; food groups with intermediate recommendations - 'milk and dairy products', 'meat, fish and eggs'; food groups for which consumption should be limited- 'sugary snacks', 'salty snacks', 'fat and sauces'; composite foods for which no specific recommendation exists because of variable composition and nutritional content - 'composite foods'; and, separately, 'beverages'. Alcoholic beverages and herbs and spices were excluded from the analyses.

Broad food categories were subdivided into detailed food categories, considering the consumer's point of view (e.g. soups included dry soups and broth, which are sold in the same supermarket aisle; see online supplementary Table S2 for categorisation of foods and beverages).

In a separate analysis, a further subcategorisation of cakes and biscuits took into account their content of fat (lipids $\geq 15 \mathrm{~g} / 100 \mathrm{~g}$ ) and added sugar $(\geq 15 \mathrm{~g} / 100 \mathrm{~g}$ ), in order to account for the PNNS recommendation 'avoid eating foods that are too salty, too sugary or too fatty' ${ }^{,(20)}$. Taking these elements into account led to categories covering all possible combinations: 'sugary and fatty snacks'; 'fatty snacks'; 'sugary snacks'; 'low-fat and -sugar snacks'.

Food Standards Agency score computation. The FSA score is computed taking into account the nutrient content per $100 \mathrm{~g}$ for foods and beverages. It allocates positive points $(0-10)$ for the content of energy $(\mathrm{kJ})$, total sugar $(\mathrm{g})$, SFA $(\mathrm{g})$ and $\mathrm{Na}(\mathrm{mg})$. Negative points $(0-5)$ are allocated for the content of fruits, vegetables and nuts, fibres and proteins. The individual score is based on a discrete continuous scale from -15 (most healthy) to +40 (less healthy) (see online supplementary Table S1).

\section{Statistical analysis}

Category evaluation. Variability in the FSA score was assessed using a multiple category system. The distribution 
was partitioned into percentiles, separately for foods and beverages in order to obtain an even number of products in each category. Given the distribution of FSA score values, the FSA score in the NutriNet-Santé food composition database was divided into quintiles for foods and into quartiles for beverages.

Foods and beverages were also categorised as 'healthier' and 'less healthy' according to the Office of Communication cut-off values: 'healthier' if FSA score $\leq 4$ ( $\leq 1$ for beverages); 'less healthy' if FSA score $>4$ ( $>1$ for beverages $)^{(13)}$.

Variability in the Food Standards Agency score across the Programme National Nutrition Santé food categories

Non-weighted analyses. Non-weighted analyses took into account all foods present in the database (including branded foods).

The mean FSA score and distribution across the detailed and broad food categories were computed. Variability in the FSA scores within each broad category was illustrated via boxplots of the distribution. Distributions in the broad and detailed food categories across the quintiles/quartiles of the FSA score were computed.

Weighted analyses. Weighted analyses took into account only generic foods that were consumed by the representative sample of the French population (i.e. including a smaller number of products). Each food was weighted according to its relative weight consumption $(\mathrm{g})$, separately for foods and beverages. Weighting was performed in order to avoid attributing the same weight to foods that are rarely consumed and to those that are very commonly consumed.

Distributions in the broad and detailed food categories across the quintiles/quartiles of the FSA score were computed. A sub-analysis also investigated the distribution of the different subgroups of 'biscuits and cakes' according to their nutritional content.

\section{Results}

The food composition database contained 3741 foods and drinks (including 2657 generic foods and 1084 branded foods). After exclusion of alcoholic beverages ( $n$ 88) and herbs and spices ( $n$ 145), 3508 foods and beverages ( $n 3331$ foods and $n 177$ beverages) were retained for non-weighted analyses. Among the 3508 foods and beverages present in the database, 2447 were generic foods ( $n 2337$ foods and $n 110$ beverages) and, finally, 1973 ( $n 1878$ foods and $n 95$ beverages) had been consumed by the representative sample from the NutriNet-Santé study, and were included in weighted analyses (see Table 1 for sociodemographic characteristics of the included sample).

Among the foods, mean FSA scores were the lowest for 'fruit and vegetables' ( -3.05 (SD 4.84)) and 'cereals and potatoes' (3.99 (SD 7.92)) and the highest for 'sugary snacks' (15.71 (SD 6.06)) and 'fats and sauces' (13.60 (SD 7.49)) (see online supplementary Table S3). Beverages had a mean FSA score of $0 \cdot 17$ (SD 2.52), with 'fruit juices' having lower mean scores than 'sweetened beverages' (-3.34 (SD 1.84) and 1.35 (SD 1.26), respectively) (see online supplementary Table S3). Distributions
Table 1. Characteristics of the representative sample from the NutriNet-Santé study ( $n$ 4225)

(Number of subjects and percentages)

\begin{tabular}{|c|c|c|}
\hline & $n$ & $\%$ \\
\hline \multicolumn{3}{|l|}{ Sex } \\
\hline Men & 2013 & $47 \cdot 6$ \\
\hline Women & 2212 & $52 \cdot 4$ \\
\hline \multicolumn{3}{|l|}{ Age (years) } \\
\hline $18-25$ & 326 & $7 \cdot 7$ \\
\hline $26-45$ & 1465 & $34 \cdot 7$ \\
\hline $46-65$ & 1610 & $38 \cdot 1$ \\
\hline$>65$ & 824 & $19 \cdot 5$ \\
\hline \multicolumn{3}{|l|}{ Educational level } \\
\hline$<12$ years & 2482 & $58 \cdot 7$ \\
\hline 12 years (high school graduation) & 682 & $16 \cdot 1$ \\
\hline $13-15$ years & 509 & $12 \cdot 0$ \\
\hline$>15$ years & 552 & $13 \cdot 1$ \\
\hline \multicolumn{3}{|l|}{ Marital status } \\
\hline Married & 3053 & $72 \cdot 3$ \\
\hline Single/divorced/widowed & 1171 & $27 \cdot 7$ \\
\hline \multicolumn{3}{|l|}{ Income (€/month) } \\
\hline$\leq 900$ & 595 & $14 \cdot 1$ \\
\hline $900-2700$ & 2813 & $66 \cdot 6$ \\
\hline$>2700$ & 817 & $19 \cdot 3$ \\
\hline \multicolumn{3}{|l|}{ Smoking status } \\
\hline Regular smoker & 522 & $12 \cdot 4$ \\
\hline Occasional smoker & 166 & 3.9 \\
\hline Former smoker & 1662 & $39 \cdot 3$ \\
\hline Never smoker & 1875 & $44 \cdot 4$ \\
\hline \multicolumn{3}{|l|}{ BMI category $\left(\mathrm{kg} / \mathrm{m}^{2}\right)$} \\
\hline$<18.5$ & 126 & 3.0 \\
\hline $18 \cdot 5-25$ & 2356 & $55 \cdot 8$ \\
\hline $25-30$ & 1225 & $29 \cdot 0$ \\
\hline$\geq 30$ & 518 & $12 \cdot 3$ \\
\hline
\end{tabular}

of the values were the widest for 'cereals and potatoes', 'salty snacks' and 'fat and sauces' (Fig. 1). The distribution was also important for composite foods, for which no specific recommendation exists, except the global recommendation 'avoid eating foods that are too salty, too sugary or too fatty' (Fig. 1). Distributions of the values were much narrower for beverages, with the category 'fruit nectars' having the widest distribution (Fig. 2).

'Healthier' foods corresponded to the first two quintiles (for foods) and to the first three quartiles (for beverages) of the FSA score distribution in the NutriNet-Santé food composition database. Distributions of the PNNS food and beverage categories across the FSA score categories were similar in non-weighted and weighted analyses (see online supplementary Tables S3 and S4 for non-weighted analyses). Broad food categories for which consumption is encouraged by the French PNNS recommendations were more likely to be in the first quintiles of the FSA score distribution: in weighted analyses, $82.41 \%$ of 'fruit and vegetables' were in the first quintile of the distribution; 38.21 and $52.23 \%$ of 'cereals and potatoes' were in the first and second quintiles of the distribution, respectively (Table 2). Conversely, broad food categories for which consumption should be limited according to the PNNS were more likely to be in the last two quintiles of the distribution: 32.57 and $21.97 \%$ of 'sugary snacks' were in the fourth and fifth quintiles of the distribution, respectively (Table 2). As hypothesised, the distribution varied importantly 


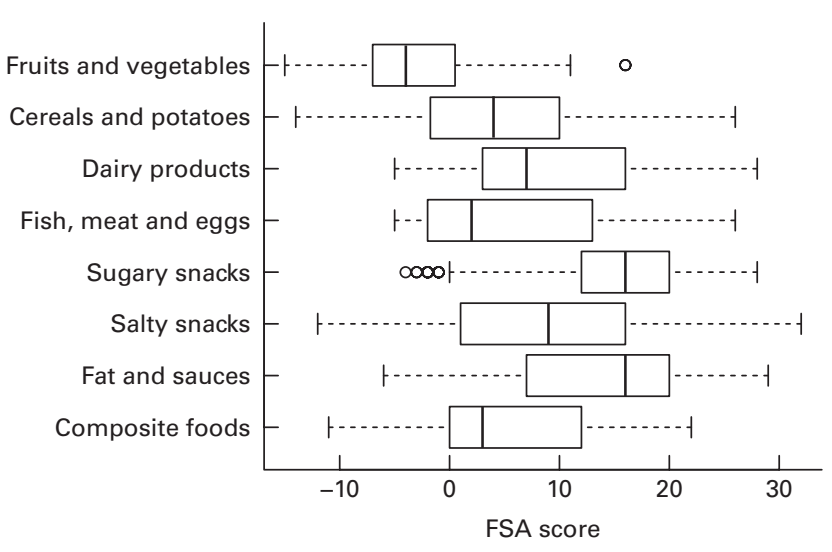

Fig. 1. Boxplot of the Food Standards Agency (FSA) score across the broad food categories in the French NutriNet-Sante food composition database (non-weighted data). The boundary of the box nearest to the right indicates the 25th percentile, the line within the box marks the median, and the boundary of the box furthest from the right indicates the 75th percentile. Whiskers (error bars) above and below the box indicate the lower limit (25th percentile $-1.5 \times$ (interquartile range)) and the upper limit (75th percentile $+1.5 \times$ (interquartile range)). The circles are individual outlier points.

across the detailed food categories: within the 'milk and dairy products' category, milk and yogurt were consistently distributed in the lower quintiles of the distribution than cheese (17.24\% in the first quintile $v \cdot 1 \cdot 16 \%$; conversely, $0 \%$ in the last quintile $v .88 .71 \%$, respectively; Table 2). Similarly, within the 'meat, fish and eggs' category, fish and seafood were consistently distributed in the lower quintiles than processed meat $(53.76 \%$ in the first quintile $v .0 \cdot 17 \%$; conversely, $0 \cdot 19 \%$ in the last quintile $v \cdot 74 \cdot 84 \%$, respectively) (Table 2). Within the 'composite foods' category, 'pizzas, pies and quiche' were more likely to be distributed in the higher quintiles than other 'one-dish meals' $26.90 \%$ in the highest quintile $v .0 .56 \%$, respectively; Table 2). Distribution in the various subgroups of 'biscuits and cakes' depending on their nutritional content in fat and sugar showed that the FSA score allowed for a consistent discrimination across the types of products, with products low in fat and sugar distributing in the lower quintiles than sugary, fatty and sugary and fatty products, though variability in the FSA score remained important (see online supplementary Table S5).

For beverages, distribution of the values did not allow for a discrimination of five evenly distributed categories, but only of four distinct quartiles. Within the 'beverages' category, 'fruit juices' were consistently distributed in the lower quartiles than all other beverages, including non-sugared beverages (including water; $98.2 \%$ of fruit juices were in the lowest quartile $v .1 \cdot 6 \%$ of non-sugared beverages; see Table 3 and online supplementary Table S6 for non-weighted analyses). Conversely, 'sweetened beverages' were more likely to be distributed in the higher quartiles $(72.5 \%$ in the highest quartile; Table 3$)$.

\section{Discussion}

The present results show that even though the FSA score has been constructed according to British public health nutritional recommendations, the model has a broader application, as it can be applied in the French context with meaningful results.

PNNS food groups were similar to British food groups used for the validation in the National Diet and Nutrition Survey food database, and they consistently scored similarly using the FSA score ${ }^{(17)}$. Using the Office of Communication cut-off values for foods, $97 \cdot 8 \%$ of 'fruit and vegetables', $77 \cdot 1 \%$ of 'milk and dairy products', $67 \cdot 4 \%$ of 'meat, fish and eggs' and $3.8 \%$ of 'sugary snacks' scored as 'healthier' in our food database, compared with, respectively $97,70,58$ and $5 \%$ in the National Diet and Nutrition Survey food database. For 'cereals and potatoes', 90.4\% were considered as 'healthier' in our database, compared with only $72 \%$ in the National Diet and Nutrition Survey. This can be related to the fact that in France, legumes that exhibited very low scores are incorporated in this group, while they are considered as alternatives to protein-rich foods in the $\mathrm{UK}^{(21)}$.

Some inconsistencies appear though, in particular for nuts. The FSA score incorporates nuts in the computation of the 'fruit, vegetable and nuts' component of the score, which accounts for their overall better score and distribution ${ }^{(13)}$. In the UK, consumption of nuts is encouraged in 'moderate' amounts $^{(21)}$. However, in France, nuts are considered as salty snacks and, as such, recommendations indicate that their consumption should be limited. However, some reflection on the PNNS recommendations is currently underway in France ${ }^{(22)}$.

The FSA score was developed in order to account for the nutrients of major concern in public health in the $\mathrm{UK}^{(14,17)}$. Compared with other nutrient profiling schemes, it has been found to be the most consistent, and has the advantage of having a sound scientific background to its construction ${ }^{(6,10)}$. The adequacy of the FSA score to French data tends to confirm that although nutrition patterns are different across countries ${ }^{(23)}$, nutritional risk factors targeted by public health authorities are similar, mirroring similar burden of diseases ${ }^{(24)}$

Beyond the ability of the FSA score to adequately position the French broad food categories in the 'healthier' and 'less healthy' categories of the Office of Communication, its

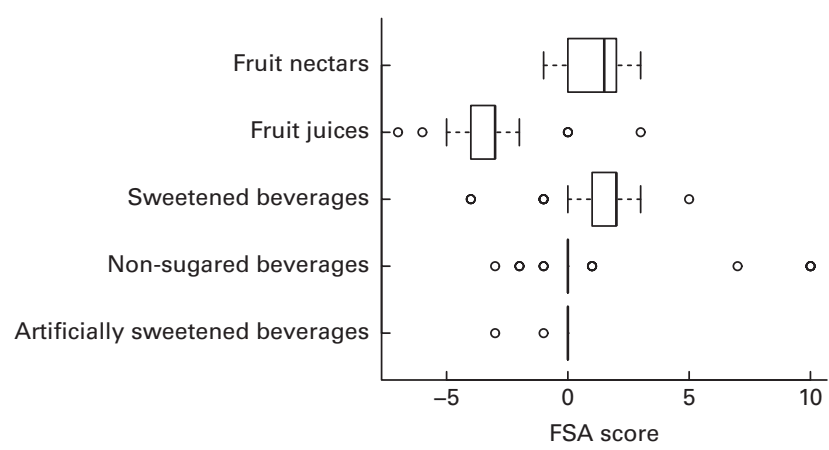

Fig. 2. Boxplot of the Food Standards Agency (FSA) score across the categories of beverages in the French NutriNet-Santé food composition database (non-weighted data). The boundary of the box nearest to the right indicates the 25th percentile, the line within the box marks the median, and the boundary of the box furthest from the right indicates the 75th percentile. Whiskers (error bars) above and below the box indicate the lower limit (25th percentile $-1.5 \times$ (interquartile range)) and the upper limit (75th percentile $+1.5 \times$ (interquartile range)). The circles are individual outlier points. 
Table 2. Weighted distribution of the broad and detailed food categories across the quintiles of the Food Standards Agency score distribution and the Office of Communication classification ( $n$ 1878) in the French NutriNet-Santé food composition database*

\begin{tabular}{|c|c|c|c|c|c|c|c|}
\hline & $\begin{array}{c}\text { Quintile } 1 \\
\text { (minimum to }-2 \text { ) }\end{array}$ & $\begin{array}{l}\text { Quintile } 2 \\
(-1 \text { to } 3)\end{array}$ & $\begin{array}{l}\text { Quintile } 3 \\
\text { (4 to } 11 \text { ) }\end{array}$ & $\begin{array}{l}\text { Quintile } 4 \\
\text { (12 to } 16)\end{array}$ & $\begin{array}{c}\text { Quintile } 5 \\
\text { (17 to maximum) }\end{array}$ & $\begin{array}{l}\text { Healthier foods } \\
\quad \leq 4\end{array}$ & $n$ \\
\hline Fruit and vegetables & 82.41 & $15 \cdot 42$ & $2 \cdot 17$ & 0 & 0 & 97.83 & 291 \\
\hline Fruits & $96 \cdot 32$ & 1.00 & $2 \cdot 68$ & 0 & 0 & $97 \cdot 32$ & 108 \\
\hline Dried fruits & 1.86 & $88 \cdot 15$ & 9.99 & 0 & 0 & $90 \cdot 01$ & 15 \\
\hline Vegetables & 98.52 & 1.46 & 0.02 & 0 & 0 & 99.98 & 117 \\
\hline Soups & 4.94 & $89 \cdot 38$ & $5 \cdot 67$ & 0 & 0 & $94 \cdot 33$ & 51 \\
\hline Cereals and potatoes & $38 \cdot 21$ & $52 \cdot 23$ & 8.36 & 0.64 & 0.56 & 90.44 & 168 \\
\hline Cereals & $66 \cdot 11$ & 33.46 & 0.27 & 0.17 & 0 & 99.56 & 39 \\
\hline Breakfast cereals & $13 \cdot 87$ & $5 \cdot 78$ & $48 \cdot 72$ & 13.63 & 17.99 & $19 \cdot 65$ & 30 \\
\hline Legumes & 100 & 0 & 0 & 0 & 0 & 100 & 11 \\
\hline Bread & $12 \cdot 41$ & $80 \cdot 37$ & 6.87 & 0.35 & 0 & $92 \cdot 78$ & 63 \\
\hline Potatoes & $58 \cdot 86$ & 21.67 & $19 \cdot 47$ & 0 & 0 & 80.53 & 25 \\
\hline Milk and dairy products & $12 \cdot 19$ & 64.94 & $5 \cdot 64$ & $5 \cdot 23$ & $12 \cdot 01$ & $77 \cdot 13$ & 237 \\
\hline Dairy desserts & 4.71 & 60.2 & $25 \cdot 03$ & 8.47 & 1.59 & 64.92 & 62 \\
\hline Cheese & $1 \cdot 16$ & 3.56 & 0.83 & $5 \cdot 74$ & 88.71 & 4.72 & 101 \\
\hline Ice cream & 0.12 & $16 \cdot 37$ & $13 \cdot 2$ & $67 \cdot 45$ & $2 \cdot 86$ & $16 \cdot 49$ & 19 \\
\hline Milk and yogurt & $17 \cdot 24$ & 81.87 & 0.89 & 0 & 0 & $99 \cdot 11$ & 55 \\
\hline Meat, fish and eggs & 33.33 & 34.07 & $11 \cdot 29$ & $8 \cdot 12$ & $13 \cdot 18$ & 67.4 & 339 \\
\hline Offals & $26 \cdot 14$ & 21.62 & $6 \cdot 27$ & 3.66 & $42 \cdot 3$ & $47 \cdot 76$ & 39 \\
\hline Processed meat & 0.17 & 8.92 & $2 \cdot 71$ & $13 \cdot 36$ & 74.84 & 9.09 & 70 \\
\hline Eggs & 0.4 & $92 \cdot 18$ & $6 \cdot 84$ & 0.58 & 0 & 92.58 & 14 \\
\hline Fish and seafood & 53.76 & $36 \cdot 14$ & $4 \cdot 12$ & 5.79 & 0.19 & 89.9 & 104 \\
\hline Meat & $40 \cdot 03$ & $32 \cdot 75$ & $18 \cdot 26$ & 8.96 & 0 & $72 \cdot 78$ & 112 \\
\hline Sugary snacks & 0.04 & 3.71 & $41 \cdot 71$ & 32.57 & 21.97 & 3.75 & 248 \\
\hline Biscuits and cakes & 0 & $6 \cdot 68$ & 40.53 & $25 \cdot 15$ & $27 \cdot 63$ & $6 \cdot 68$ & 156 \\
\hline Chocolate products & 0 & 0 & 13.55 & 13.24 & 73.21 & 0 & 28 \\
\hline Sweets & 0.17 & 0.22 & 61.42 & 37.54 & 0.65 & 0.38 & 52 \\
\hline Pastries & 0 & 0.09 & $29 \cdot 38$ & 70.53 & 0 & 0.09 & 12 \\
\hline Salty snacks & 31.65 & 10.52 & 21.64 & $16 \cdot 67$ & 19.51 & $42 \cdot 17$ & 61 \\
\hline Nuts & 68.33 & $23 \cdot 2$ & 8.46 & 0 & 0 & 91.54 & 35 \\
\hline Appetisers & $2 \cdot 69$ & 0.51 & 32.05 & 29.84 & 34.92 & $3 \cdot 2$ & 26 \\
\hline Fat and sauces & $2 \cdot 1$ & 3.77 & 5.89 & 21.67 & 66.57 & $5 \cdot 87$ & 109 \\
\hline Fats & 0 & 0.54 & 1.59 & $24 \cdot 32$ & 73.55 & 0.54 & 50 \\
\hline Dressings and sauces & 5.79 & 9.45 & 13.46 & 17 & 54.3 & $15 \cdot 24$ & 59 \\
\hline Composite foods & $19 \cdot 79$ & 45.54 & 14.85 & 13.67 & $6 \cdot 15$ & 65.33 & 425 \\
\hline Pizzas, pies and quiche & 0.31 & $6 \cdot 34$ & 29.52 & 36.94 & $26 \cdot 9$ & 6.65 & 69 \\
\hline One-dish meals & $26 \cdot 43$ & $58 \cdot 32$ & 9.58 & 5.11 & 0.56 & 84.75 & 301 \\
\hline Sandwich & 0.88 & 14.02 & 32.02 & 43.22 & 9.86 & 14.9 & 55 \\
\hline
\end{tabular}

${ }^{\star}$ Foods were weighted according to their relative consumption in a sample of NutriNet-Santé participants, representative of the French population ( $n$ 4225).

variability and ability to discriminate between and within detailed food categories questions its use as a dichotomised score. Such a binary score induces the idea of 'good' and 'bad' foods, promoting dichotomous thinking ${ }^{(25)}$. Use of more than two categories reflecting 'nutritional quality' would achieve the initial aim of the scoring procedure, i.e. classifying foods according to their overall nutritional quality without the drawback of classifying foods as 'all good' or 'all bad'. Moreover, for an application as a front-of-package nutritional information system, multiple categories (e.g. five, as in the present study) could entice manufacturers to use it as a competitive tool, and improve the nutritional quality of their products.

Variability within groups using the FSA score categories allows for a discrimination between products that would otherwise have a similar 'nutrition' appeal to consumers, thus complementing current recommendations on the consumption of global food groups. This is most apparent for the 'breakfast cereals' subgroup, which, given their inclusion in the 'cereals and potatoes' group, would correspond to the

Table 3. Weighted distribution of beverage categories across the quartiles of the Food Standards Agency score distribution and the Office of Communication classification ( $n$ 95) in the French NutriNet-Santé food composition database*

\begin{tabular}{|c|c|c|c|c|c|c|}
\hline & $\begin{array}{c}\text { Quartile } 1 \\
\text { (minimum to }-1 \text { ) }\end{array}$ & $\begin{array}{l}\text { Quartile } 2 \\
(0 \text { to } 0)\end{array}$ & $\begin{array}{c}\text { Quartile } 3 \\
\text { (1 to } 1)\end{array}$ & $\begin{array}{c}\text { Quartile } 4 \\
\text { (2 to maximum) }\end{array}$ & $\begin{array}{l}\text { Healthier beverages } \\
\leq \leq 1\end{array}$ & $n$ \\
\hline \multicolumn{7}{|l|}{ Beverages } \\
\hline Artificially sweetened beverages & $0 \cdot 2$ & $99 \cdot 8$ & 0 & 0 & 100 & 7 \\
\hline Non-sugared beverages & 1.6 & $98 \cdot 3$ & $0 \cdot 1$ & 0 & $99 \cdot 9$ & 32 \\
\hline Sweetened beverages & 1.7 & $10 \cdot 9$ & 14.9 & $72 \cdot 5$ & $12 \cdot 6$ & 22 \\
\hline Fruit juices & $98 \cdot 2$ & 0.4 & 0 & 1.4 & $98 \cdot 6$ & 26 \\
\hline Fruit nectars & $9 \cdot 5$ & $34 \cdot 7$ & $17 \cdot 8$ & $38 \cdot 1$ & $44 \cdot 2$ & 8 \\
\hline
\end{tabular}

* Beverages were weighted according to their relative consumption in a sample of NutriNet-Santé participants, representative of the French population ( $n$ 4225). 
recommendation of 'eat at every meal, depending on appetite'. However, breakfast cereals are distributed across all quintiles, and, in fact, some $18 \%$ of them appear in the last quintile. The use of the FSA score in five categories would therefore allow consumers to discriminate between differing nutritional qualities within breakfast cereals: oat flakes (in the first quintile) and chocolate muesli (in the last quintile). This can be extended to other categories: in the 'fruits' category, some products appear in the third quintile (fruits in syrup); in the 'sugary snacks' category, though most of the products appear in high quintiles, which correspond to the recommendation 'avoid snacking', some still have fairly good scores (biscuits containing fruits in the second quintile); moreover, nutritional content of 'sugary snacks' was consistently taken into account by the FSA score, as confirmed by our additional analysis; finally, in the 'composite foods' category, foods appear in all quintiles, and even within the 'pizza' subcategory, some appear as having better nutritional quality than others (four-seasons pizza $v$. four-cheese pizza).

From a statistical point of view, given the distribution of the FSA score values, we were not able to divide beverages into more than four even categories. Moreover, the second and third quartiles corresponded to only one point in the FSA score. Such distribution of values questions the computation of the score for beverages, for which different threshold values of the 'total sugar' or 'energy density' could be considered to better represent the diversity of the existing market.

At present, the present study supports the contention of using multiple categories of the FSA score for foods, but does not support it for beverages. Considering multiple categories for beverages (e.g. five, to be consistent with foods) would therefore entail modifying the score computation system.

The present study is subject to some limitations. First, we only assessed content validity of the FSA score. Variability in the score within one food group depends not only on the group (and variability within recipes and products), but also on the structure of the food database. Our database reflects the usual French diet, but does not accurately represent the French food market, which would be the actual target of the FSA score implementation. Future developments should investigate the application of the FSA score in the actual food market environment. Moreover, we used dietary data from volunteer subjects participating in a nutritional cohort. Food choices in these participants could differ from those in the general population, as subjects are more likely to be aware of nutritional issues. However, non-weighted and weighted data conveyed similar results, suggesting that the extent of this bias was limited.

\section{Conclusion}

The FSA score, even if developed in the specific context of the regulation of advertising to children in the UK, appears to be applicable in the French context. However, its use could be enlarged beyond the current dichotomised 'healthier' and 'less healthy' categories, at least for foods. Future studies should also investigate whether the FSA score can adequately describe an individual's diet.

\section{Supplementary material}

To view supplementary material for this article, please visit http://dx.doi.org/10.1017/S0007114514002761

\section{Acknowledgements}

The authors thank Gwenael Monot, Paul Flanzy, Mohand Ait Oufella, Yasmina Chelghoum, Than Duong Van (computer scientists), Florence Charpentier (dietitian), Anne-Sylvie Monot-Berroyer (communications assistant), Nathalie Arnault, Veronique Gourlet, Fabien Szabo, Laurent Bourhis, Stephen Besseau (statisticians) and Rachida Mehroug (logistics assistant) for their technical contribution to the NutriNetSanté study, and all dedicated and conscientious volunteers.

The authors thank Voluntis (a healthcare software company) and MXS (a software company specialising in dietary assessment tools) for developing the NutriNet-Santé Web-based interface according to our guidelines.

The NutriNet-Santé Study was supported by the French Ministry of Health, the Institut de Veille Sanitaire, the Institut National de la Santé et de la Recherche Médicale, the Institut National de la Recherche Agronomique, the Conservatoire National des Arts et Métiers, the Institut National de Prévention et d'Education pour la Santé and the Fondation pour la Recherche Médicale and Paris 13 University. The funders had no role in the study design, data collection, analysis and interpretation of the data and writing of the article, or in the decision to publish or the preparation of the manuscript. All authors had access to all the data.

The authors' contributions are as follows: C. J. wrote the statistical analysis plan, analysed the data, and drafted and revised the paper; E. K.-G. participated in the statistical analysis plan, analysed the data and critically revised the paper for important intellectual content; M. T., C. M. and L. F. analysed the data and critically revised the paper for important intellectual content; S. H. designed the data collection tools, implemented the study, monitored the data collection for the whole study, and revised the draft of the manuscript.

None of the authors has any conflict of interest to declare.

\section{References}

1. World Health Organization (2003) Diet, Nutrition and the Prevention of Chronic Diseases. Report of a Joint WHO/ FAO Expert Consultation. WHO Technical Report Series no. 916. Geneva: WHO.

2. World Health Organization (2009) Global Health Risks: Mortality and Burden of Disease Attributable to Selected Major Risks. Geneva: WHO.

3. Hughes R (2004) Competencies for effective public health nutrition practice: a developing consensus. Public Health Nutr 7, 683-691.

4. Serra-Majem L (2009) Moving forward in public health nutrition - the I World Congress of Public Health Nutrition. Introduction. Nutr Rev 67, S2-S6.

5. Lachat C, Van Camp J, De Henauw S, et al. (2005) A concise overview of national nutrition action plans in the European Union Member States. Public Health Nutr 8, 266-274. 
6. Azais-Braesco V, Goffi C \& Labouze E (2006) Nutrient profiling: comparison and critical analysis of existing systems. Public Health Nutr 9, 613-622.

7. Hercberg S, Chat-Yung S \& Chauliac M (2008) The French National Nutrition and Health Program: 2001-2006-2010. Int J Public Health 53, 68-77.

8. Institut National de Prévention et d'Education pour la Santé (2002) La santé vient en mangeant. Le guide alimentaire pour tous (PNNS Adults Food Guide). Paris: INPES.

9. Tetens I, Oberdoerfer R, Madsen C, et al. (2007) Nutritional characterisation of foods: science-based approach to nutrient profiling. Summary report of an ILSI Europe workshop held in April 2006. Eur J Nutr 46, 4-14.

10. Garsetti M, de Vries J, Smith M, et al. (2007) Nutrient profiling schemes: overview and comparative analysis. Eur J Nutr $\mathbf{4 6}$, $15-28$.

11. Lobstein T \& Davies S (2009) Defining and labelling 'healthy' and 'unhealthy' food. Public Health Nutr 12, 331-340.

12. Townsend MS (2010) Where is the science? What will it take to show that nutrient profiling systems work? Am J Clin Nutr 91, 1109S-1115S

13. Rayner M, Scarborough P \& Lobstein $T$ (2009) The UK Ofcom Nutrient Profiling Model - defining 'healthy' and 'unhealthy' food and drinks for TV advertising to children. http://www.dph.ox.ac.uk/bhfhprg/publicationsandreports/ acad-publications/bhfhprgpublished/nutrientprofilemodel (accessed 16 January 2014).

14. Rayner M, Scarborough P \& Stockley L, et al. (2005) Nutrient profiles: development of final model. Final report. http://tna. europarchive.org/20120102091535/http://www.food.gov.uk/ multimedia/pdfs/nutprofr.pdf (accessed 16 January 2014).

15. Nnoaham KE, Sacks G, Rayner M, et al. (2009) Modelling income group differences in the health and economic impacts of targeted food taxes and subsidies. Int J Epidemiol 38, 1324-1333.

16. Rayner M, Scarborough P \& Stockley L (2005) Nutrient Profiles: Applicability of Currently Proposed Model for Uses in Relation to Promotion of Foods in Children Aged 5-10 and Adults. London: FSA. http://www.food.gov.uk/ multimedia/pdfs/nutprofmodelforadults.pdf (accessed 16 January 2014).

17. Arambepola C, Scarborough P \& Rayner M (2008) Validating a nutrient profile model. Public Health Nutr 11, 371-378.

18. Hercberg S, Castetbon K, Czernichow S, et al. (2010) The Nutrinet-Santé Study: a web-based prospective study on the relationship between nutrition and health and determinants of dietary patterns and nutritional status. BMC Public Health 10, 242.

19. Etude Nutrinet-Santé (2013) Table de composition des aliments de l'étude Nutrinet-Santé (Nutrinet-Santé Study Food Composition Database). Paris: Economica.

20. Mejean C, Macouillard P, Castetbon K, et al. (2011) Socioeconomic, demographic, lifestyle and health characteristics associated with consumption of fatty-sweetened and fattysalted foods in middle-aged French adults. Br J Nutr 105, $776-786$

21. Food Standard Agency (2006) FSA Nutrient and Food Based Guideline for UK Institutions. London: FSA. http://www. food.gov.uk/multimedia/pdfs/nutguideuk.pdf (accessed 24 July 2014)

22. ANSES - Agence nationale de sécurité sanitaire de l'alimentation de l'environnement et du travail (2013) Les apports nutritionnels conseillés (Recommended dietary allowances). http://www.anses.fr/fr/content/les-apports-nutritionnels-con seill\%C3\%A9s (accessed 25 July 2014).

23. Slimani N, Fahey M, Welch AA, et al. (2002) Diversity of dietary patterns observed in the European Prospective Investigation into Cancer and Nutrition (EPIC) project. Public Health Nutr 5, 1311-1328.

24. Pomerleau J, Mckee M, Lobstein T, et al. (2003) The burden of disease attributable to nutrition in Europe. Public Health Nutr 6, 453-461.

25. Nitzke S \& Freeland-Graves J (2007) Position of the American Dietetic Association: total diet approach to communicating food and nutrition information. J Am Diet Assoc 107, $1224-1232$. 